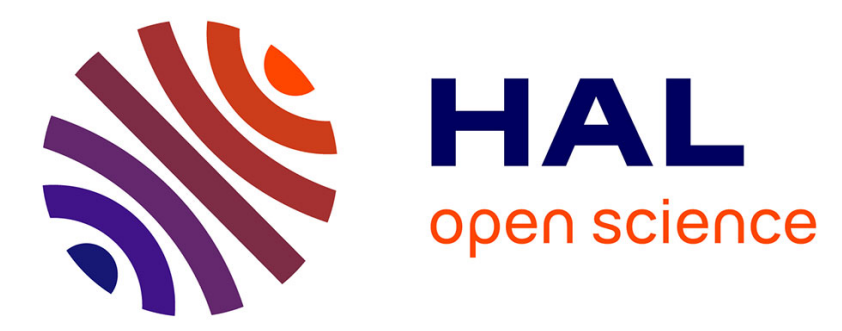

\title{
A mesomodel for localisation and damage computation in laminates
}

Pierre Ladevèze, Olivier Allix, Jean-François Deü, David Lévêque

\section{To cite this version:}

Pierre Ladevèze, Olivier Allix, Jean-François Deü, David Lévêque. A mesomodel for localisation and damage computation in laminates. Computer Methods in Applied Mechanics and Engineering, 2000, 183 (1-2), pp.105-122. 10.1016/S0045-7825(99)00214-5 . hal-01745223

\section{HAL Id: hal-01745223 \\ https://hal.science/hal-01745223}

Submitted on 19 Aug 2019

HAL is a multi-disciplinary open access archive for the deposit and dissemination of scientific research documents, whether they are published or not. The documents may come from teaching and research institutions in France or abroad, or from public or private research centers.
L'archive ouverte pluridisciplinaire HAL, est destinée au dépôt et à la diffusion de documents scientifiques de niveau recherche, publiés ou non, émanant des établissements d'enseignement et de recherche français ou étrangers, des laboratoires publics ou privés. 


\title{
A mesomodel for localisation and damage computation in laminates
}

\author{
Pierre Ladevèze *, Olivier Allix, Jean-François Deü, David Lévêque \\ ENS Cachan/CNRS/Universite Paris 6, Laboratoire de Mecanique et Technologie, 61, Avenue du Président Wilson, 94235 Cachan Cedex, \\ France
}

\begin{abstract}
The basic aspects of a material mesomodel dedicated to composite laminates and capable of simulating complete fracture phenomena are discussed. Attention is focused herein on damage computation and, in particular, on the description of localisation phenomena. Both quasi-static and dynamic loadings are considered.
\end{abstract}

\section{Introduction}

One of the main challenges in composite design is to compute the damage state of a composite structure subjected to complex loading at any point and at any time until final fracture. Damage refers to the more or less gradual development of microcracks which lead to macrocracks and then to rupture; macrocracks are simulated as completely damaged zones.

For composites and especially composite laminates, damage is generally of a highly complex nature. Brittle and progressive damage mechanisms are both present (cf. Fig. 1). There is not one single, but rather several damage mechanisms. They are highly anisotropic and display a strong unilateral feature which depends on whether the microcracks are closed or open.

The first and probably the main difficulty is to derive, at the chosen scale, an appropriate damage model, i.e. a model that is compatible with all information coming from the micro, meso and macro scales. Our approach, which has been achieved in other studies, is to define what we call a laminate mesomodel. This model is defined at the mesoscale characterised by the thickness of the plies [1]. Then, the laminated structure is described as a stacking sequence of homogeneous layers throughout the thickness and interlaminar interfaces. For both of the two basic constituents, i.e. the ply and the interface, material models are introduced using the internal variables framework for specifying the material's state: inelastic strains, damage variables, hardening variables, etc. The main damage mechanisms are described as: fibre breaking, matrix micro-cracking and adjacent layers debonding. The single-layer model includes both damage and inelasticity [1-5]. A comprehensive presentation has been given in the book of Herakovitch [6]. The interlaminar interface is defined as a two-dimensional mechanical model which ensures traction and displacement transfer from one ply to another. Its mechanical behaviour depends on the angle between the fibres of two adjacent layers [7-9]. Let us note that these same material models can be used in dynamics [10].

\footnotetext{
${ }^{*}$ Corresponding author. Tel.: +33-1-47-40-22-38; fax: +33-1-47-40-22-40.

E-mail address: ladeveze@1mt.ens-cachan.fr (P. Ladevèze).
} 


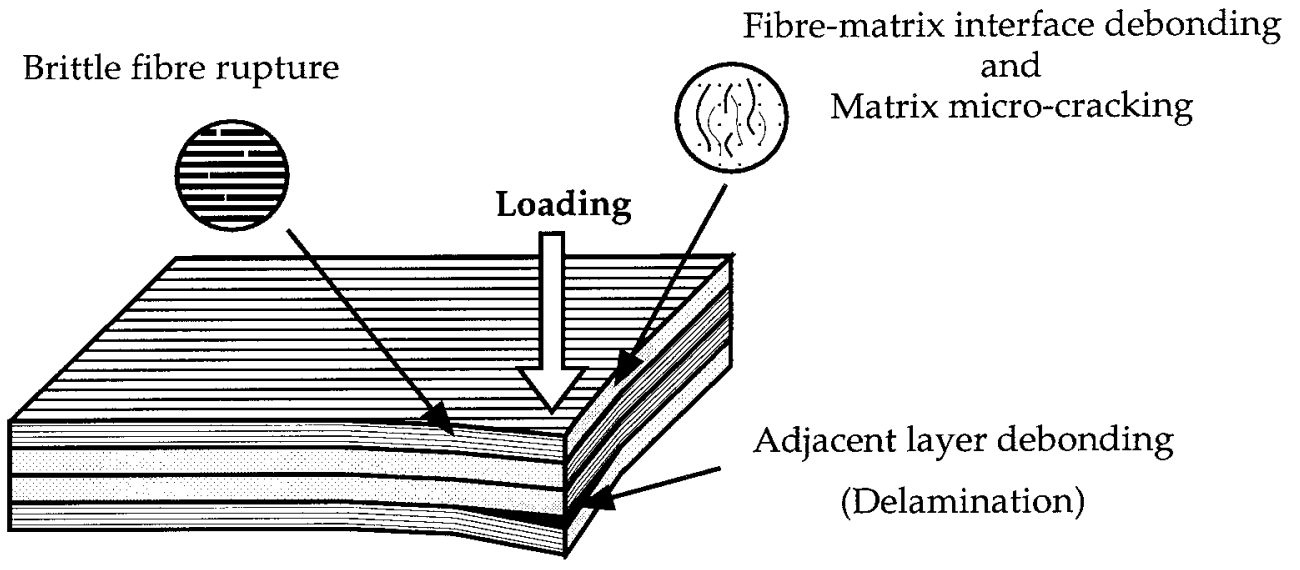

Fig. 1. Damage and failure mechanisms.

Other contributions to damage mechanics for laminates can be found particularly in [11-14]. Other recent contributions are provided in the book edited by Voyiadjis, Ju and Chaboche [15].

In this paper, we seek to outline only the modelling difficulties and the current state-of-the-art. However, a new and improved damage model associated with the out-of-plane stresses is introduced. Most examples concern carbon/epoxy composite laminates.

The second difficulty concerns fracture simulation. It is now rather well-known that classical damage models present serious shortcomings. For example, they do not contain classical linear fracture mechanics, which is quite effective in many cases. One solution is provided by the localisation limiter concept introduced in $[16,17]$. This is a regularisation procedure which introduces additional terms built either from a non-local approach or from a second gradient approach. Viscoplastic regularisation can also be introduced. Further developments are given in [18-23].

Our solution for composites and especially laminated structures is based on what we call a damage mesomodel. It is a semi-discrete model for which the damage state is locally uniform within the mesoconstituents [7,24]. For laminates, it is uniform throughout the thickness of each single layer; as a complement, continuum damage models with delay effects are introduced. The possibilities of such an approach have been demonstrated for quasi-static loading in [25-27]. In this paper, we go further considering dynamic loading. Moreover, we present new comparisons between simulations and experimental results for delamination tests carried out on a laminated holed plate in tension.

\section{Mesomodelling of laminates}

In our pragmatic approach, the characteristic length is the thickness of the plies. The mesomodel is defined by means of two mesoconstituents:

- the single layer,

- the interface, which is a mechanical surface connecting two adjacent layers and depending on the relative orientation of their fibres (Fig. 2).

The damage mechanisms are taken into account by means of internal damage variables. A mesomodel is then defined by adding another property: a uniform damage state is prescribed throughout the thickness of the elementary ply. This point plays a major role when trying to simulate a crack with a damage model. As a complement, delayed damage models are introduced.

One limitation of the proposed mesomodel is that the fracture of the material is described by means of only two types of macrocracks:

- delamination cracks within the interfaces,

- cracks, orthogonal to the laminate mid-plane, with each cracked layer being completely cracked throughout its thickness. 


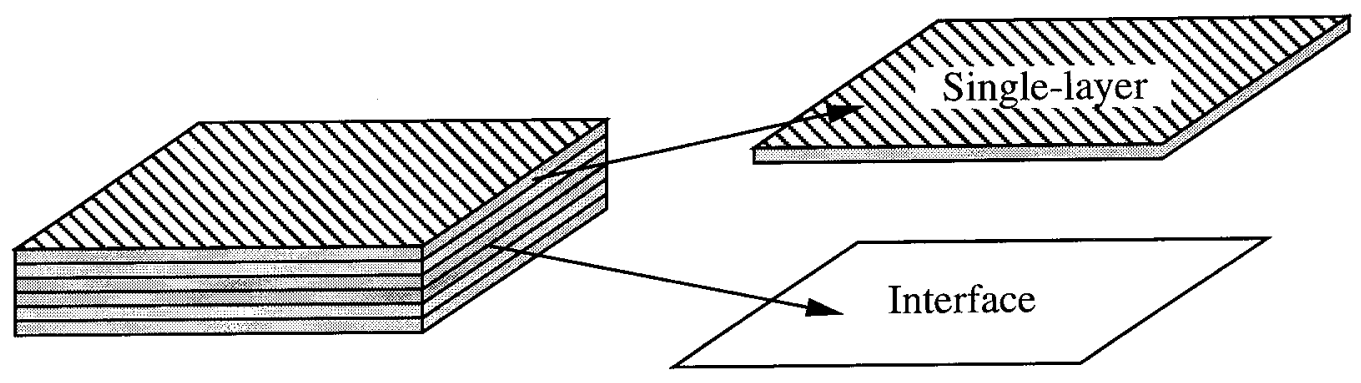

Fig. 2. Laminate modelling.

Another limitation is that very severe dynamic loading cannot be studied; the dynamic wavelength must be larger than the thickness of the plies.

\section{Single-layer modelling}

\subsection{Damage kinematics}

The composite materials (e.g. carbon-fibre/epoxy-resin) under consideration in this study have only one reinforced direction. In what follows, the subscripts 1, 2 and 3 designate respectively the fibre direction, the transverse direction inside the layer and the normal direction. The energy of the damaged material defines the damage kinematics. Using common notations, this energy is:

$$
\begin{aligned}
& E_{\mathrm{D}} \equiv \frac{1}{2\left(1-d_{F}\right)}\left[\frac{\left\langle\sigma_{11}\right\rangle^{2}}{E_{1}^{0}}+\frac{\varnothing\left(\left\langle-\sigma_{11}\right\rangle\right)}{E_{1}^{0}}-\left(\frac{v_{21}^{0}}{E_{2}^{0}}+\frac{v_{12}^{0}}{E_{1}^{0}}\right) \times \sigma_{11} \sigma_{22}-\left(\frac{v_{31}^{0}}{E_{3}^{0}}+\frac{v_{13}^{0}}{E_{1}^{0}}\right) \sigma_{11} \sigma_{33}\right. \\
& \left.-\left(\frac{v_{32}^{0}}{E_{3}^{0}}+\frac{v_{23}^{0}}{E_{2}^{0}}\right) \sigma_{22} \sigma_{33}\right]+\frac{\left\langle-\sigma_{22}\right\rangle^{2}}{E_{2}^{0}}+\frac{\left\langle-\sigma_{33}\right\rangle^{2}}{E_{3}^{0}} \\
& \left.+\frac{1}{2}\left[\frac{1}{\left(1-d^{\prime}\right)} \frac{\left\langle\sigma_{22}\right\rangle^{2}}{E_{2}^{0}}+\frac{\left\langle\sigma_{33}\right\rangle^{2}}{E_{3}^{0}}\right)+\frac{1}{(1-d)}\left(\frac{\sigma_{12}^{2}}{G_{12}^{0}}+\frac{\sigma_{23}^{2}}{G_{23}^{0}}+\frac{\sigma_{31}^{2}}{G_{31}^{0}}\right)\right]
\end{aligned}
$$

$\varnothing$ is a material function which takes into account the non-linear response in compression [3]. $d_{F}, d$ and $d^{\prime}$ are three scalar internal variables which remain constant within the thickness of each single-layer and serve to describe the damage mechanisms inside. The unilateral aspect of microcracking is taken into account by splitting the energy into a "tension" energy and a "compression" energy; $\langle\cdot\rangle$ denotes the positive part. The thermodynamic forces associated with the mechanical dissipation are:

$$
\begin{aligned}
& Y_{d} \equiv \frac{\partial}{\partial d}\left\langle\left\langle E_{\mathrm{D}}\right\rangle\right\rangle_{\mid \boldsymbol{\sigma}: \text { cst }}=\frac{1}{2(1-d)^{2}}\left\langle\left\langle\frac{\sigma_{12}^{2}}{G_{12}^{0}}+\frac{\sigma_{23}^{2}}{G_{23}^{0}}+\frac{\sigma_{31}^{2}}{G_{31}^{0}}\right\rangle\right\rangle, \\
& Y_{d^{\prime}} \equiv \frac{\partial}{\partial d^{\prime}}\left\langle\left\langle E_{\mathrm{D}}\right\rangle\right\rangle_{\mid \sigma: \text { cst }}=\frac{1}{2\left(1-d^{\prime}\right)^{2}}\left\langle\left\langle\frac{\left\langle\sigma_{22}\right\rangle^{2}}{E_{2}^{0}}+\frac{\left\langle\sigma_{33}\right\rangle^{2}}{E_{3}^{0}}\right\rangle\right\rangle, \\
& Y_{F} \equiv \frac{\partial}{\partial d_{F}}\left\langle\left\langle E_{\mathrm{D}}\right\rangle\right\rangle_{\mid \sigma: \text { cst }} \\
& =\frac{1}{2\left(1-d_{F}\right)^{2}}\left\langle\left\langle\frac{\left\langle\sigma_{11}\right\rangle^{2}}{E_{1}^{0}}+\frac{\varnothing\left(\left\langle-\sigma_{11}\right\rangle\right)}{E_{1}^{0}}-\left(\frac{v_{12}^{0}}{E_{1}^{0}}+\frac{v_{21}^{0}}{E_{2}^{0}}\right) \sigma_{11} \sigma_{22}\right.\right. \\
& \left.\left.-\left(\frac{v_{13}^{0}}{E_{1}^{0}}+\frac{v_{31}^{0}}{E_{3}^{0}}\right) \sigma_{11} \sigma_{33}-\left(\frac{v_{32}^{0}}{E_{3}^{0}}+\frac{v_{23}^{0}}{E_{2}^{0}}\right) \sigma_{22} \sigma_{33}\right\rangle\right\rangle
\end{aligned}
$$

$\langle\langle\rangle$.$\rangle denotes the mean value within the thickness.$ 
Remark. In previous papers, the damage related to out-of-plane stresses $\sigma_{13}, \sigma_{23}$ and $\sigma_{33}$ has been taken into account only in the interface model. We were not able to separate what happens for the plies from what happens for the interfaces. Here, expression (1) introduces a better damage model taking advantage of a material transverse isotropy property.

\subsection{Damage evolution law}

From experimental results, it follows that the governing forces of damage evolution are

$$
Y=\left[Y_{d}+b Y_{d^{\prime}}\right], \quad Y^{\prime}=\left[Y_{d^{\prime}}+b^{\prime} Y_{d}\right], \quad Y_{F},
$$

where $b$ and $b^{\prime}$ are material constants which balance the transverse energy's influence and the shear energy's influence. For small damage rates, we get:

$$
\begin{aligned}
& d=f_{d}\left(\underline{Y}^{1 / 2}\right) \quad \text { for } d \leqslant 1, \\
& d^{\prime}=f_{d^{\prime}}\left(\underline{Y}^{1^{1 / 2}}\right) \text { for } d^{\prime} \leqslant 1, \\
& d_{F}=f_{F}\left(\underline{Y}_{F}^{1 / 2}\right) \text { for } d_{F} \leqslant 1,
\end{aligned}
$$

where:

$$
\underline{r}_{\mid t}=\sup _{\tau \leqslant t} r_{\mid \tau},
$$

$f_{d}, f_{d^{\prime}}$ and $f_{F}$ are material functions [2]; both progressive and brittle damage evolutions are present. For large damage rates, we have introduced a damage model with delay effects (cf. Fig. 3):

$$
\dot{d}=\frac{1}{\tau_{\mathrm{c}}}\left[1-\exp \left(-a\left\langle f_{d}\left(Y^{1 / 2}\right)-d\right\rangle\right)\right] \quad \text { if } d<1, d=1 \text { otherwise, }
$$

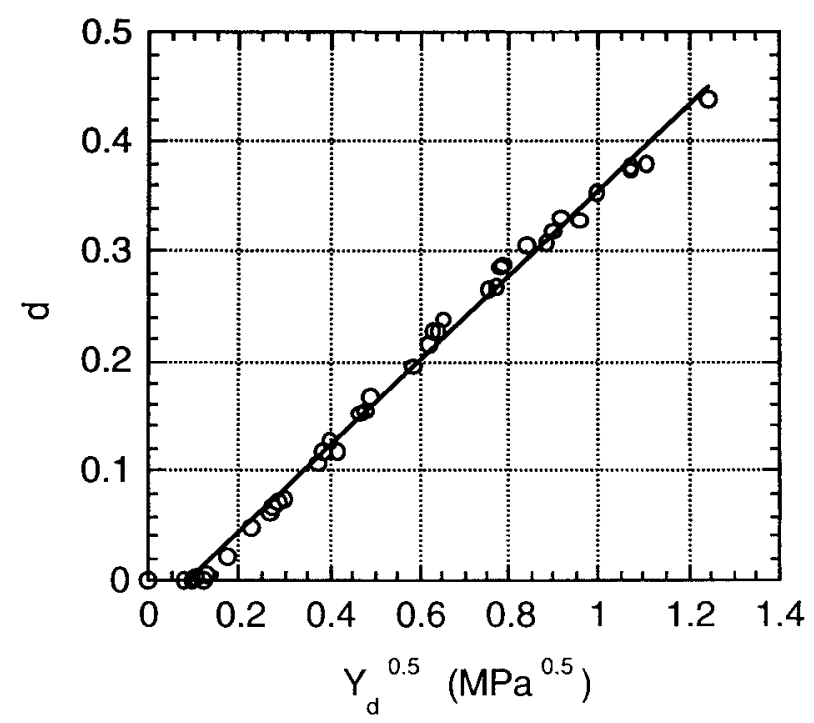

Fig. 3. Shear damage material function $Y_{d}^{1 / 2} \rightarrow f_{d}\left(Y_{d}^{1 / 2}\right)$ of the single-layer for the M55J/M18 material. 


$$
\begin{aligned}
& \dot{d}^{\prime}=\frac{1}{\tau_{\mathrm{c}}}\left[1-\exp \left(-a\left\langle f_{d}^{\prime}\left(Y^{\prime^{1 / 2}}\right)-d^{\prime}\right\rangle\right)\right] \quad \text { if } d^{\prime}<1, d^{\prime}=1 \text { otherwise, } \\
& \dot{d}_{F}=\frac{1}{\tau_{\mathrm{c}}}\left[1-\exp \left(-a\left\langle f_{F}\left(Y_{F}^{1 / 2}\right)-d_{F}\right\rangle\right)\right] \quad \text { if } d_{F}<1, d_{\mathrm{F}}=1 \text { otherwise }
\end{aligned}
$$

The same material constants, $\tau_{\mathrm{c}}$ and $a$, are taken for the three damage evolutions laws. For this damage model with delay effects, the variations of the forces $Y, Y^{\prime}$ and $Y_{F}$ do not lead to instantaneous variations of the damage variables $d, d^{\prime}$ and $d_{F}$. There is a certain delay, defined by the characteristic time $\tau_{\mathrm{c}}$. Moreover, a maximum damage rate, which is $1 / \tau_{\mathrm{c}}$, does exist. Let us also note herein that a clear distinction can be made between this damage model with delay effects and viscoelastic or viscoplastic models: the characteristic time introduced in the damage model with delay effects is several orders of magnitude less than in the viscous case. This characteristic time is, in fact, related to the fracture process.

Remark. In compression, the material model involves a quasi-brittle criterion; no progressive damage is introduced here.

\subsection{Inelastic strain - damagelplasticity (or viscoplasticity) coupling}

The microcracks, i.e. the damage, lead to sliding with friction and thus to inelastic strains. The idea, which seems to work quite well, is to base the model on "effective" quantities:

- effective stress $\widetilde{\boldsymbol{\sigma}}$,

- effective inelastic strain $\widetilde{\boldsymbol{\varepsilon}}_{p}$ which satisfy:

$$
\operatorname{Tr}\left[\boldsymbol{\sigma} \dot{\boldsymbol{\varepsilon}}_{p}\right]=\operatorname{Tr}\left[\tilde{\boldsymbol{\sigma}} \tilde{\dot{\boldsymbol{\varepsilon}}}_{p}\right] .
$$

Here, we take:

$$
\begin{aligned}
& \tilde{\sigma}_{11}=\sigma_{11}, \quad \tilde{\sigma}_{22}=\frac{\left\langle\sigma_{22}\right\rangle}{\left(1-d^{\prime}\right)}-\left\langle-\sigma_{22}\right\rangle, \quad \tilde{\sigma}_{33}=\frac{\left\langle\sigma_{33}\right\rangle}{\left(1-d^{\prime}\right)}-\left\langle-\sigma_{33}\right\rangle, \\
& \tilde{\sigma}_{12}=\frac{\sigma_{12}}{1-d}, \quad \tilde{\sigma}_{23}=\frac{\sigma_{23}}{1-d}, \quad \tilde{\sigma}_{13}=\frac{\sigma_{13}}{1-d} .
\end{aligned}
$$

Evolution laws are described by the classical plastic or viscoplastic models upon effective quantities. For carbon/epoxy laminates, a plastic associated model has been derived in [2]. It is assumed that no plastic behaviour occurs in the fibre direction. Then, the elasticity domain can be defined for 3D stresses by:

$$
f(\tilde{\boldsymbol{\sigma}}, \tilde{R})=\left[\tilde{\sigma}_{12}^{2}+\tilde{\sigma}_{23}^{2}+\tilde{\sigma}_{13}^{2}+c^{2}\left(\tilde{\sigma}_{22}^{2}+\tilde{\sigma}_{33}^{2}\right)\right]^{1 / 2}-\tilde{R} \leqslant 0,
$$

where $\tilde{R}$ is the threshold and $c$ a material coupling constant. Moreover, one has:

$$
\tilde{R} \equiv g(\tilde{p})
$$

where $g$ is the material hardening function, with $\tilde{p}$ being the accumulated plastic strain.

\subsection{Identification}

Such a single-layer model (excepted for the constants $\tau_{\mathrm{c}}$ and $a$ ) has been identified for quite a number of materials. Further details and some results are reported in [2-6]. We will discuss later on the identification of the two constants $\tau_{\mathrm{c}}$ and $a$. 


\section{Interlaminar interface model}

\subsection{Damage kinematics of the interface}

The interlaminar connection is thus modelled as a two-dimensional entity which ensures stress and displacement transfers from one ply to another. The interlaminar connection can be classically interpreted as a ply of matrix whose thickness (denoted by $e$ ) is small compared to the in-plane dimension.

$$
[U]=U^{+}-U^{-}=\left[U_{1}\right] N_{1}+\left[U_{2}\right] N_{2}+\left[U_{3}\right] N_{3}
$$

denotes the difference in displacements between the upper and lower surfaces of the "3D interface". Thus, at the first order, the strain energy is

$$
E_{\mathrm{D}} \approx \frac{1}{2} e \int_{\Gamma} \frac{[U]^{\mathrm{T}}}{e} \boldsymbol{H} \frac{[U]}{e} \mathrm{~d} \Gamma
$$

where $\Gamma$ is the area of the mid-plane interface, and $\boldsymbol{H}$ is a $(3,3)$ symmetrical matrix. For the $2 \mathrm{D}$ interface model, $[U]$ is the displacement discontinuity between two adjacent layers. We assume that the bisectors $\left(N_{1}\right.$ and $N_{2}$ ) of the angle formed by the fibre directions of the adjacent plies are orthotropic directions (cf. Fig. 4). The interface material model is built following the same approach used for deriving the single-layer model. The effect of the deterioration of the interlaminar connection is taken into account by means of internal damage variables. The behaviours in tension and in compression are distinguished by splitting the strain energy into a "tension energy" and a "compression-energy". More precisely, we use the following expression for the energy per unit area:

$$
E_{\mathrm{D}}=\frac{1}{2} \int_{\Gamma}\left[\frac{\left\langle-\sigma_{33}\right\rangle^{2}}{k_{3}^{0}}+\frac{\left\langle\sigma_{33}\right\rangle^{2}}{k_{3}^{0}\left(1-d_{3}\right)}+\frac{\sigma_{13}^{2}}{k_{1}^{0}\left(1-d_{1}\right)}+\frac{\sigma_{23}^{2}}{k_{2}^{0}\left(1-d_{2}\right)}\right] \mathrm{d} \Gamma .
$$

Three internal damage indicators, associated with the three Fracture Mechanics modes, are thereby introduced.

Remark. The used value of the interface "thickness" e is generally e $\approx \frac{1}{10}$ mini (thickness adjacent plies).

\subsection{Damage evolution laws of the interface}

These evolution laws must satisfy the Clausius-Duheim inequality. Classically, the damage forces, associated with the dissipated energy $\omega$, are introduced as follows

$$
Y_{d_{3}} \equiv \frac{1}{2} \frac{\left\langle\sigma_{33}\right\rangle^{2}}{k_{3}^{0}\left(1-d_{3}\right)^{2}} ; \quad Y_{d_{1}} \equiv \frac{1}{2} \frac{\sigma_{31}^{2}}{k_{1}^{0}\left(1-d_{1}\right)^{2}} ; \quad Y_{d_{2}} \equiv \frac{1}{2} \frac{\sigma_{32}^{2}}{k_{2}^{0}\left(1-d_{2}\right)^{2}},
$$

with: $\omega=Y_{d_{3}} \dot{d}_{3}+Y_{d_{1}} \dot{d}_{1}+Y_{d_{2}} \dot{d}_{2}(\omega \geqslant 0)$

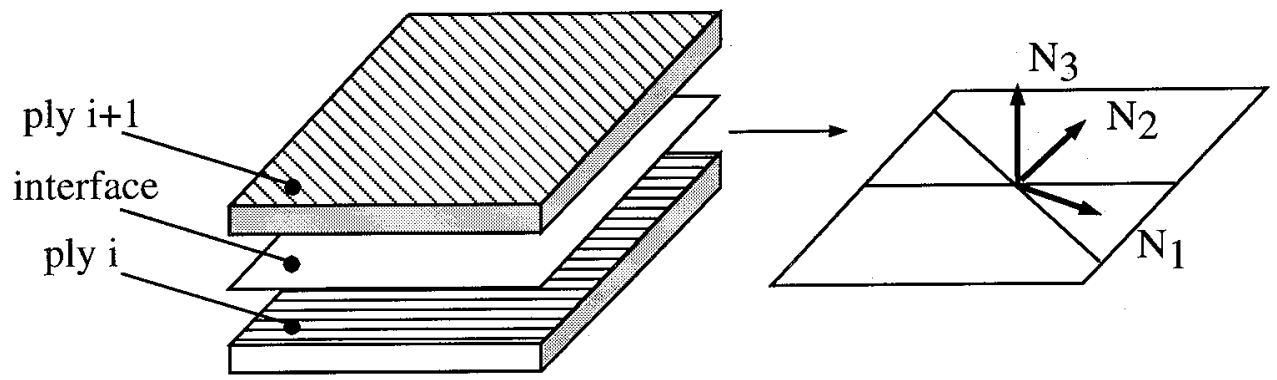

Fig. 4. "Orthotropic" directions of the interface. 
All the quantities $d_{1}, d_{2}, d_{3}, Y_{d_{3}}, Y_{d_{1}}, Y_{d_{2}}$ are defined on the surface occupied by the interface. The damage evolution laws used in this study are based on the assumption that the evolutions of the various damage indicators are strongly coupled and driven by a unique equivalent damage force. The following model considers that the damage evolution is governed by means of the following equivalent damage force:

$$
\begin{aligned}
& Y(t) \equiv\left[\left(Y_{d_{3}}^{\alpha}+\left(\gamma_{1} Y_{d_{1}}\right)^{\alpha}+\left(\gamma_{2} Y_{d_{2}}\right)^{\alpha}\right)^{1 / \alpha}\right], \\
& \underline{Y}_{t} \equiv \sup _{\tau \leqslant t} Y_{\left.\right|_{\tau}},
\end{aligned}
$$

where $\gamma_{1}, \gamma_{2}$ and $\alpha$ are material parameters. In terms of delamination modes, the first term is associated with the first opening mode, and the two others are associated with the second and third modes. A damage evolution law is then defined by the choice of a material function $W$, such that

$$
W(\underline{Y})=\left[\frac{n}{n+1} \frac{\left\langle\underline{Y}-Y_{0}\right\rangle}{Y_{\mathrm{c}}-Y_{0}}\right]^{n}
$$

where a critical value $Y_{\mathrm{c}}$ and a threshold value $Y_{0}$ are introduced. A high value of $n$ corresponds to a brittle interface. For small damage rates, one obtains

$$
d_{3}=d_{1}=d_{2} \approx W(\underline{Y}) \quad \text { if } d<1 ; \quad d_{3}=d_{1}=d_{2}=1 \quad \text { otherwise. }
$$

In the general case, a damage model with delay effects is used

$$
\begin{aligned}
& \dot{\delta}=\dot{d}_{3}=\dot{d}_{1}=\dot{d}_{2}=\frac{1}{\tau_{\mathrm{c}}^{\prime}}\left[1-\exp \left(-a^{\prime}\langle W(Y)-\delta\rangle\right)\right] \quad \text { if } \delta<1, \\
& \delta=d_{3}=d_{1}=d_{2}=1 \quad \text { otherwise. }
\end{aligned}
$$

It follows that for the completely destroyed interface zone, one has:

- $\delta=d_{3}=d_{1}=d_{2}=1$;

- classical contact conditions with a certain rigidity in the direction orthogonal to the interface.

For the complementary part of the interface, the damage rates are

$$
\dot{\delta}=\dot{d}_{1}=\dot{d}_{2}=\dot{d}_{3}=\frac{1}{\tau_{\mathrm{c}}^{\prime}}\left[1-\exp \left(-a^{\prime}\langle W(Y)-\delta\rangle\right)\right] .
$$

To summarise, the damage evolution law is defined, except for $\tau_{\mathrm{c}}^{\prime}$ and $a^{\prime}$, by means of six intrinsic material parameters $Y_{\mathrm{c}}, Y_{0}, \gamma_{1}, \gamma_{2}, \alpha$ and $n$. The threshold $Y_{0}$ is introduced here in order to expand the possibility of describing both the initiation of a delamination crack and its propagation. As regards the initiation of a delamination crack, the significant parameters are $Y_{0}, n$ and $\alpha$. It will be shown hereafter that $Y_{\mathrm{c}}, Y_{0}, \gamma_{1}, \gamma_{2}$ and $\alpha$ are related to the critical damage forces.

\subsection{Identification of the interface model's material constants}

A simple way to identify the various material constants is by comparing the mechanical dissipation yielded by our damage mechanics approach and classical linear fracture mechanics; classical delamination tests are used [27-30]. One main result reported in [27] is that the interface parameters seem to be independent of $\theta$ for all $\pm \theta$ interfaces with $\theta \neq 0^{\circ}$. Let us also note that the $\left(0^{\circ} / 0^{\circ}\right)$ interface appears to be something artificial. However, such an "artificial" interface can be introduced, for example, to describe a crack inside a thick layer. It should also be pointed out that the same model is applicable for both delamination propagation and delamination initiation.

\section{Remarks.}

- The direction $N_{1}, N_{2}$ are fixed unit vectors. They are not associated to the delamination front but to the fibre directions of the adjacent plies. 
- $\gamma_{1}$ and $\gamma_{2}$ characterise the ratio between interface toughness in mode II and mode I, and mode III and mode I, respectively. Until now, we have taken practically:

$\gamma_{1}=\gamma_{2}$.

The $\alpha$ value can be different from 2; its value is identified from the measured interface toughness for combined delamination modes. Interface material parameters have been characterised in [27-30]. $\tau_{c}^{\prime}$, a could be identified using pressure-shear impact test [48]; however, they do not play an important role for fracture prediction in most engineering quasi-static situations.

- The different damage indicators must be equal for the completely destroyed zones; their value is one. It follows that to define same damage rate for mode I, II and III is very convenient for calculation; it means that the interface damage state is characterised by a scalar state internal variable. However, a model with different damage rate for mode I, II, and III is given in $[8,25,26]$.

\section{Qualitative analysis of the damage model with delay effects}

In order to investigate the performance of the damage model with delay effects, we consider the classical example of a bar (see [20,31]).

The analysis is based on a simple one-dimensional damage model with only one scalar damage variable. The model is defined by its strain energy, $E_{\mathrm{D}}$, which is split into two parts according to whether the cracks are closed or open.

$$
\begin{aligned}
& \sigma=E^{0}(1-d)\langle\varepsilon\rangle+E^{0}\langle-\varepsilon\rangle, \\
& E_{\mathrm{D}}=\frac{1}{2}\left[\frac{\langle\sigma\rangle^{2}}{E^{0}(1-d)}+\frac{\langle-\sigma\rangle^{2}}{E^{0}}\right], \\
& Y=\frac{\partial E_{\mathrm{D}}}{\partial d_{\mid \sigma \cdot \mathrm{cst}}}=\frac{\langle\sigma\rangle^{2}}{2 E^{0}(1-d)^{2}}=\frac{E^{0}\langle\varepsilon\rangle^{2}}{2},
\end{aligned}
$$

where $Y$ is the damage energy release rate. $Y$ is assumed to drive the damage evolution. In fact, for many long-fibre composites and for a progressive damage mode, a typical quasi-static damage evolution law, for slow damage rates, is:
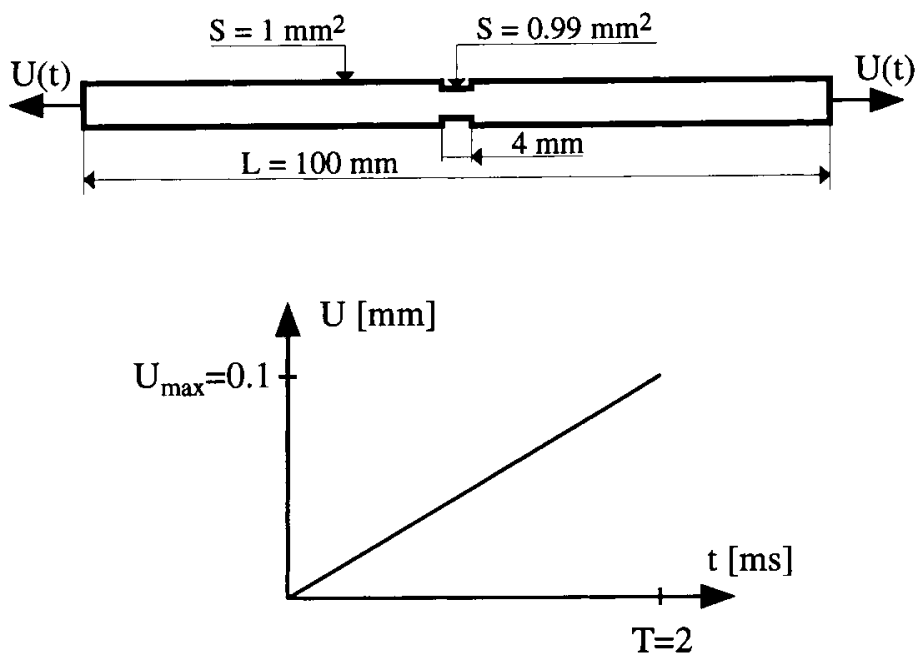

Fig. 5. One-dimensional bar problem. 


$$
\left\{\begin{array} { l l } 
{ d = f ( \underline { Y } ) } & { \text { if } d < 1 } \\
{ d = 1 } & { \text { otherwise } }
\end{array} \text { with } \left\{\begin{array}{l}
\underline{Y}_{t}=\sup _{\tau \leqslant \mathrm{t}} Y_{\tau} \\
f(\underline{Y})=\left\langle\frac{\sqrt{\underline{Y}}-\sqrt{Y_{0}}}{\sqrt{Y_{\mathrm{c}}}}\right\rangle,
\end{array}\right.\right.
$$

The corresponding damage model with delay effects is:

$$
\dot{d}=\frac{1}{\tau_{\mathrm{c}}}\left[1-\exp \left(-a^{\prime}\langle f(Y)-d\rangle\right)\right] \quad \text { if } d<1, \quad d=1 \quad \text { otherwise. }
$$

Inelasticity has not been introduced herein. Previous works have illustrated the consistency of the damage model with delay effects for rapid varying loading $([26,10,27])$. Here, rather slow varying loadings

\section{Model parameters}

Elasticity: $E^{0}=57 \mathrm{GPa}, \rho=2280 \mathrm{~kg} / \mathrm{m}^{3}$ and $\mathrm{C}_{\mathrm{e}}=5000 \mathrm{~m} / \mathrm{s}$

Damage: $\mathrm{Y}_{0}=0.05 \mathrm{MPa}, \mathrm{Y}_{\mathrm{c}}=0.23 \mathrm{MPa}, \tau_{\mathrm{c}}=20 \mu \mathrm{s}$ and $\mathrm{a}=1$

\section{Discretisation}

Number of elements: ne $=200$

Time step: $\Delta \mathrm{t}=0.5 \mu \mathrm{s}$

HHT algorithm: $\alpha=-0.05, \beta=(1-\alpha)^{2 / 4}$ and $\gamma=1 / 2-\alpha$

Fig. 6. Data and calculation characteristics.

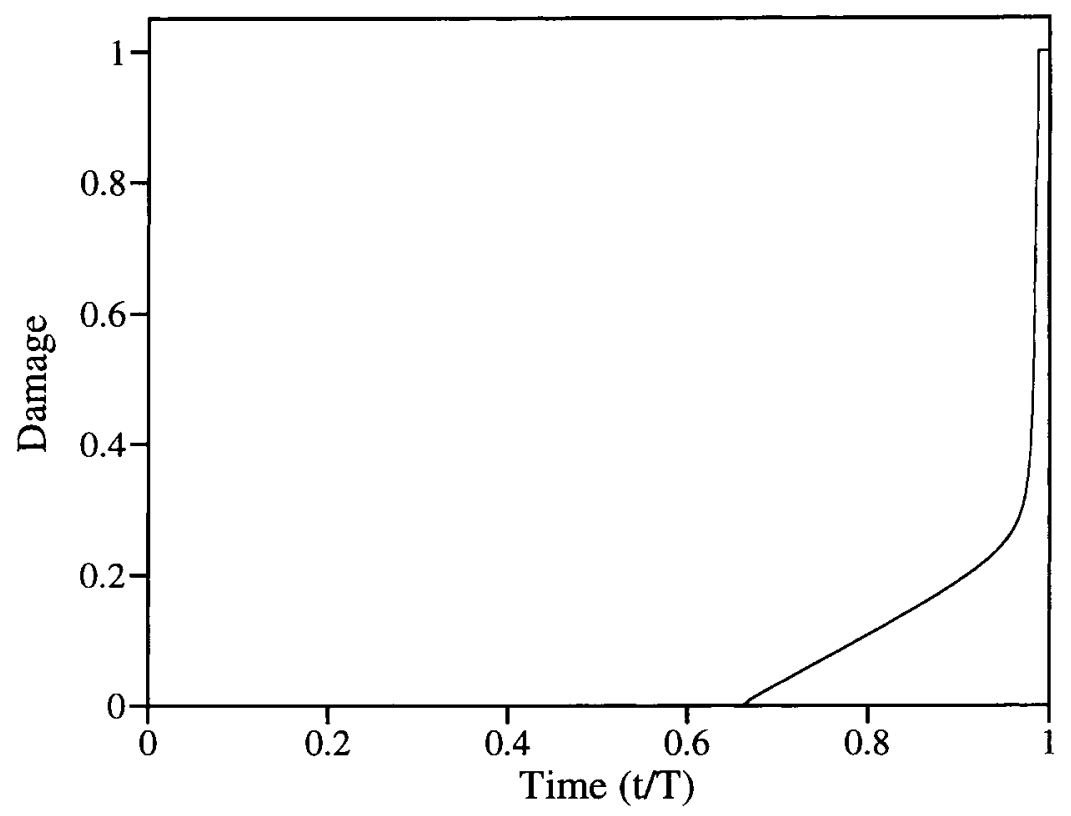

Fig. 7. Damage-time evolution at the bar's centre. 
are considered. The HHT algorithm is used [32]. The results presented concern a bar in which a defect has been introduced (one percent smallest section at the centre of the bar; see Fig. 5). Data and calculation characteristics are given in Fig. 6. Fig. 7 shows the damage-time evolution at the bar's centre. The characteristic time $\tau_{\mathrm{c}}$ introduced in our model influences the maximum slope of the damage-time evolution (i.e.: $1 / \tau_{\mathrm{c}}$ is the maximum damage rate seen in Fig. 8).

Fig. 9 presents the damage map for the bar at the last loading time $(T=2 \mathrm{~ms})$. A completely destroyed zone, i.e. a crack, occurs at the middle part of the bar. The results obtained for different meshes are plotted

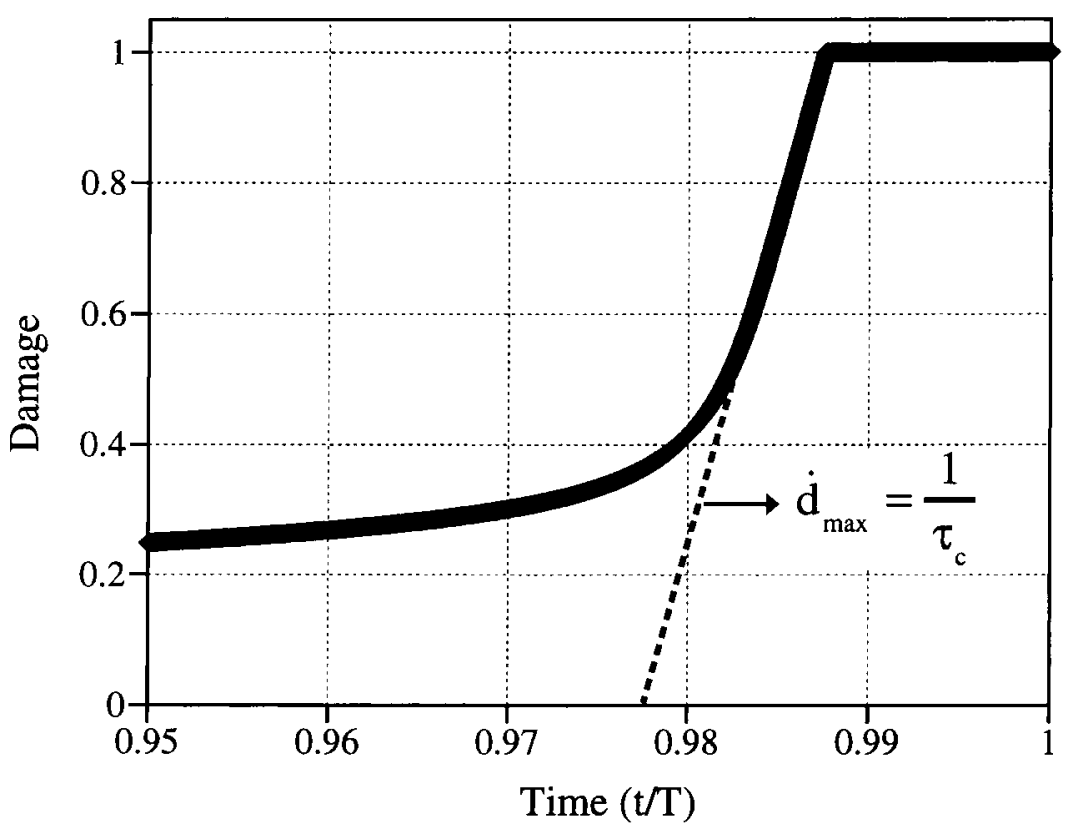

Fig. 8. Zoom of the damage-time evolution at the bar's centre.

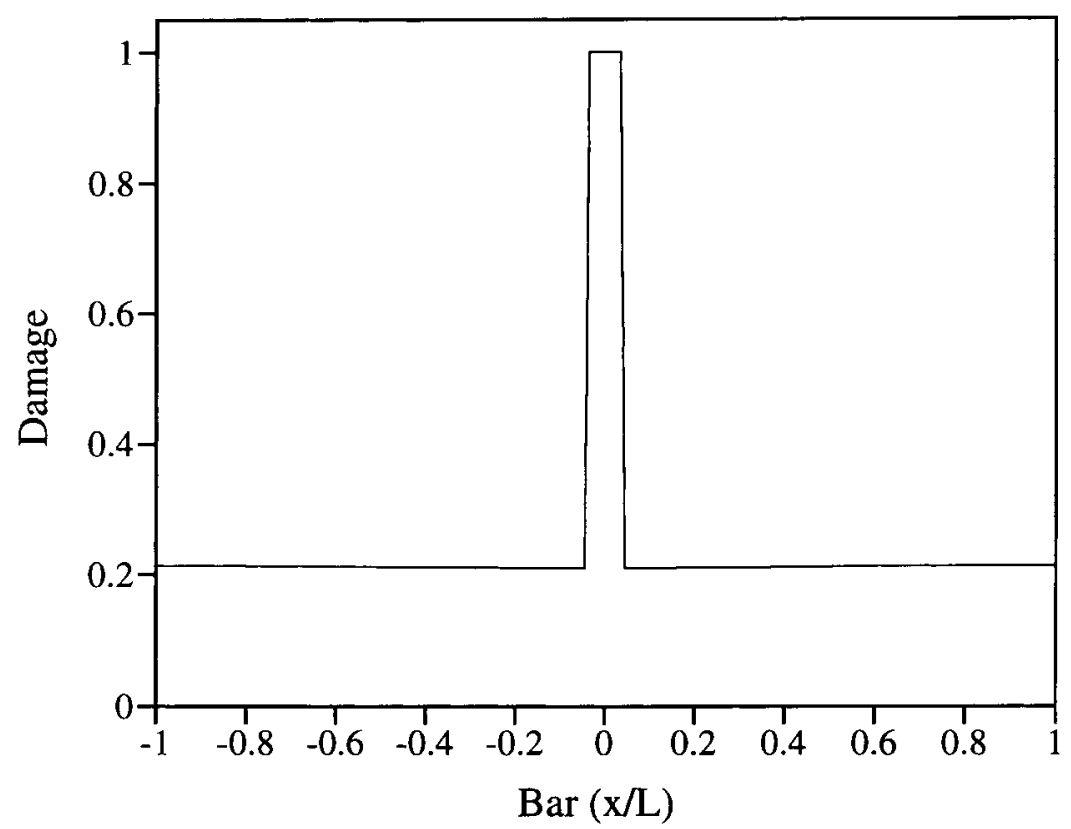

Fig. 9. Bar damage state at time $2 \mathrm{~ms}$. 
in Fig. 10. It can be seen that numerical results do not depend on the mesh size: from 100 to 400 elements, the cracked part is always the same. Finally, Fig. 11 displays the global load versus the prescribed end displacement. All of these results demonstrate that fracture phenomena are well described by a damage model with delay effects. The influence of the material parameters $\tau_{\mathrm{c}}$ and $a$ is studied in [10]. Moreover,

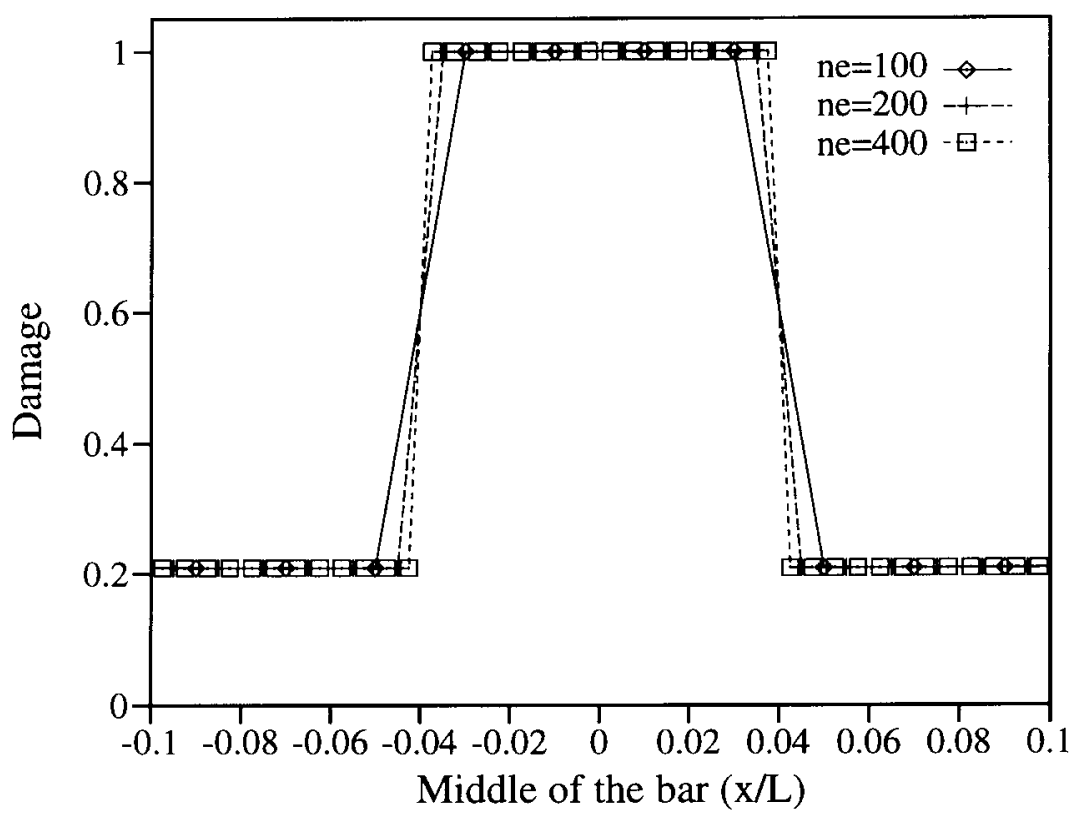

Fig. 10. Zoom of the bar damage state of the central zone at time $2 \mathrm{~ms}$.

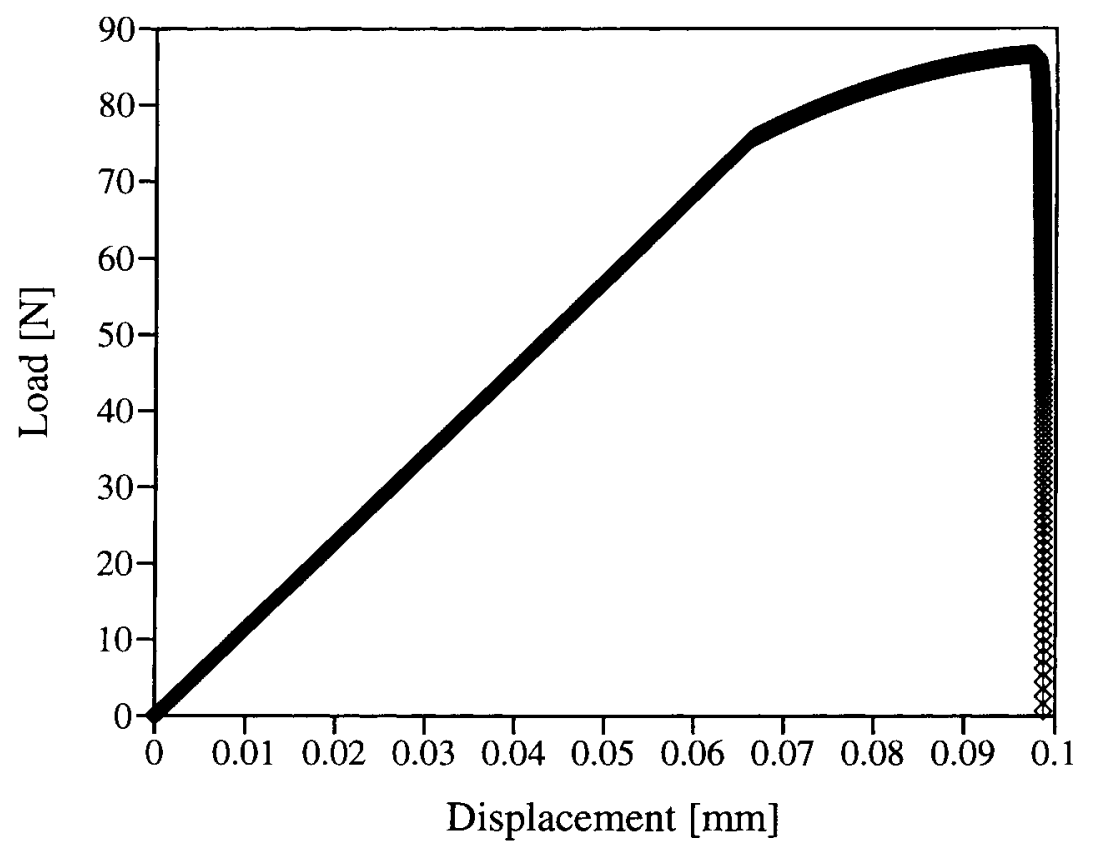

Fig. 11. Load versus the bar's end displacement. 
when introducing several macrodefects, the damage localisation and hence the final fracture occurs only on the largest of them.

\section{Delamination computation for quasi-static loading}

Most of the research works, conducted on delamination problems, have only taken into account the interlaminar degradation; damage mechanisms inside the plies are not introduced [28,33,34]. An isoparametric joint/interface element is used in [35]. Experimental results can be found in [27,29,36-44].

Herein, we consider the complete laminate mesomodel; hence all damage mechanisms are taken into account. Let us recall that our identification methodology for the interlaminar interface model has, until now, been based on several standard delamination tests (edge delamination tension test or Fracture Mechanics tests). More information can be found in [9,29,30]. Previous computation works have dealt with such experimental tests in order to compare the model's prediction with experimental results. Satisfactory conclusions have been drawn in $[9,27,30]$.

In what follows, we present a comparison between our mesomodel's predictions and experimental observations of an M55J/M18 (high-modulus carbon-fibre/epoxy-resin) $\left[0_{3} / \pm 45_{2} / 90\right]_{\mathrm{s}}$ laminate loaded in tension. A specialised software called Delamination Simulation by Damage Mechanics (DSDM), previously developed for predicting delamination around initially circular holes (see [45]), has been used. The specimen is $50 \mathrm{~mm}$ in width and $150 \mathrm{~mm}$ in guage length, and the hole diameter is $10 \mathrm{~mm}$. The test was conducted in tension on an INSTRON testing machine at a fixed displacement rate of $0.5 \mathrm{~mm} \mathrm{~min}^{-1}$. Fig. 12 shows the evolution of the X-ray revealed damage map near the hole for an increasing applied load. The fist damage, appearing at $55 \%$ of the rupture load (Fig. 12a), is transverse cracking in $90^{\circ}$-plies near the hole, and matrix cracking in the $0^{\circ}$-plies tangent to the hole in the fibre direction, which is called "splitting". Delamination only begins at about $80 \%$ of the rupture load (Fig. 12b). Just before rupture (Fig. 12c), the delaminated area is always located between the two splittings and developed in the $0^{\circ}$-direction with a length of about two hole diameters.

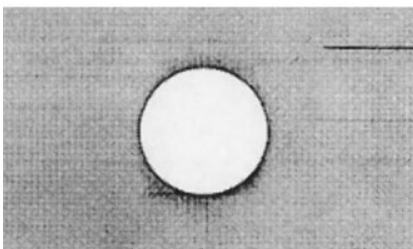

a) $55 \%$ of rupture load

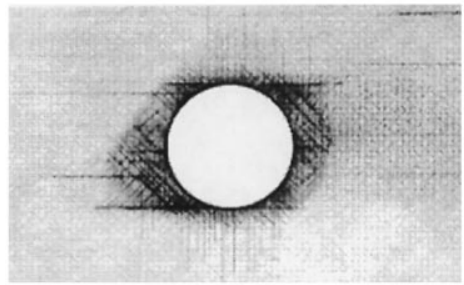

b) $86 \%$ of rupture load

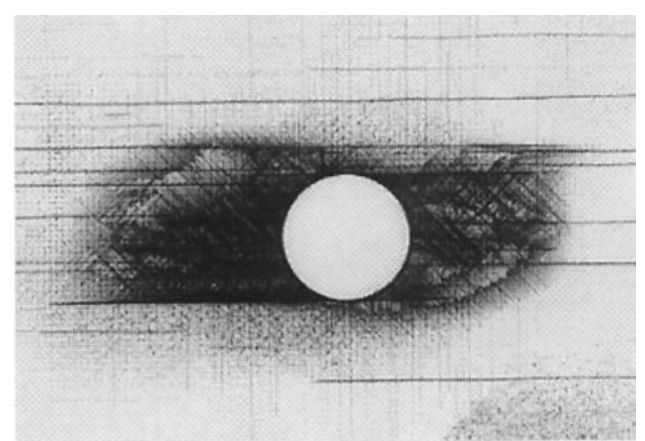

c) $99 \%$ of rupture load

Fig. 12. X-ray photographs $(\times 1.5)$ of an M55J/M18 $\left[0_{3} / \pm 45_{2} / 90\right]_{\mathrm{s}}$ holed-specimen (rupture load: $\left.430 \mathrm{MPa}\right)$.

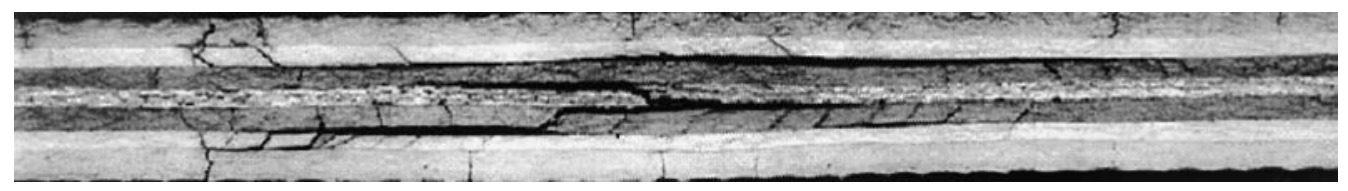

Fig. 13. Micrograph of a section tangent to the hole of a $\left[0_{3} / \pm 45_{2} / 90\right]_{\mathrm{s}}$ specimen at $92 \%$ of the rupture load. 


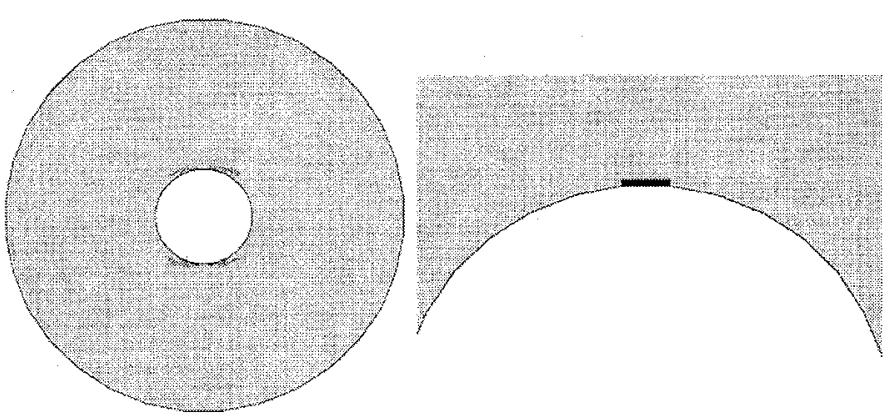

a) $\mathrm{d}$ indicator in the $0^{\circ}$-layers
b) fibre rupture in the $0^{\circ}$-layer

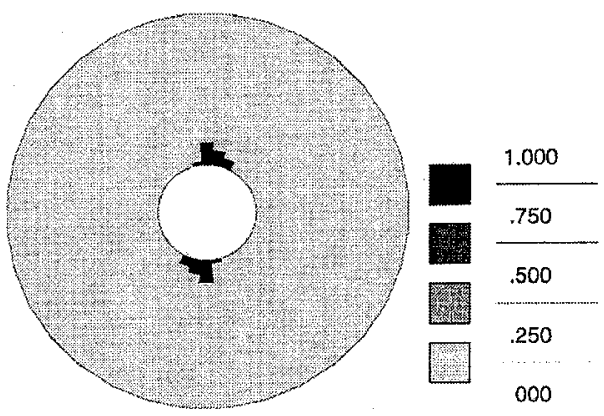

c) d' indicator in the $90^{\circ}$-layers d) " $\mathrm{d}_{i}$ " value scale

Fig. 14. Damage maps computed in the layers of a $\left[0_{3} / \pm 45_{2} / 90\right]_{\mathrm{s}}$ holed-specimen at the rupture load.

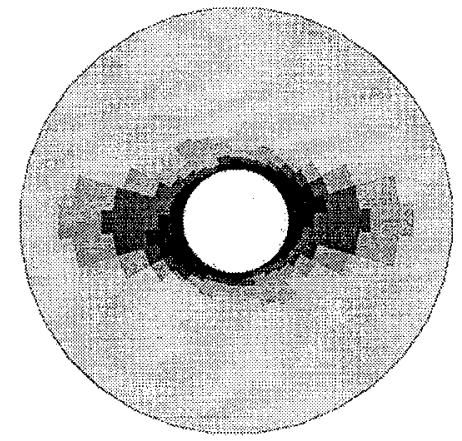

a) $\mathrm{d}_{3}$ indicator at the $\pm 45^{\circ}$ interface

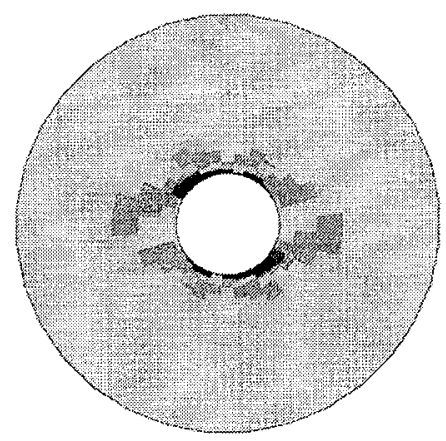

b) $d_{3}$ indicator at the $0^{\circ} / 45^{\circ}$ interface

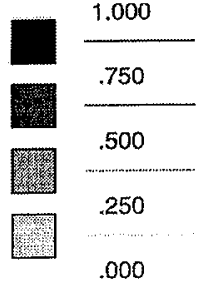

c) " $\mathrm{d}_{\mathrm{i}}$ " value scale

Fig. 15. Damage maps computed at the interfaces of a $\left[03_{3} / \pm 45_{2} / 90\right]_{\mathrm{s}}$ holed-specimen at the rupture load.

Micrographs were performed and show (see Fig. 13) that the damage is well-developed in several ways: splittings, transverse cracking (not only in the $90^{\circ}$-plies, but also in the $\pm 45^{\circ}$-plies), multiple delamination at the $0^{\circ} / 45^{\circ}, \pm 45^{\circ}$ (the most heavily damaged) and $-45^{\circ} / 90^{\circ}$ interfaces.

From the computation, the splitting can be seen as a shear damage in the $0^{\circ}$-layer (see Fig. 14a). In fact, when the fist $0^{\circ}$-fibres near the hole crack (Fig. 14b), the local load is transferred by shear in the matrix to the adjacent fibres. Transverse cracking in the $90^{\circ}$-layers is found to extend from the free-edge of the hole (Fig. 14c).

As an example, the delaminated area computed in the $\pm 45^{\circ}$ interface is shown in Fig. 15a (the delaminated area corresponds to $\left.d_{3}=1\right)$. In the same manner, the other interfaces are found to be less damaged. Fig. $15 \mathrm{~b}$ shows the damage map for the $0 \% 45^{\circ}$ interface.

\section{Remark.}

- The values of the material constants $\tau_{\mathrm{c}}, \tau_{\mathrm{c}}^{\prime}, a, a^{\prime}$ do not play an important role in such fracture prediction.

- The initiation identification with standard delamination tests is not very reliable. A new procedure which is in progress consists of using delamination tests conducted on laminated plates with a circular hole; such tests have proved to be much more reliable. This procedure requires complex $3 D$ calculations. 

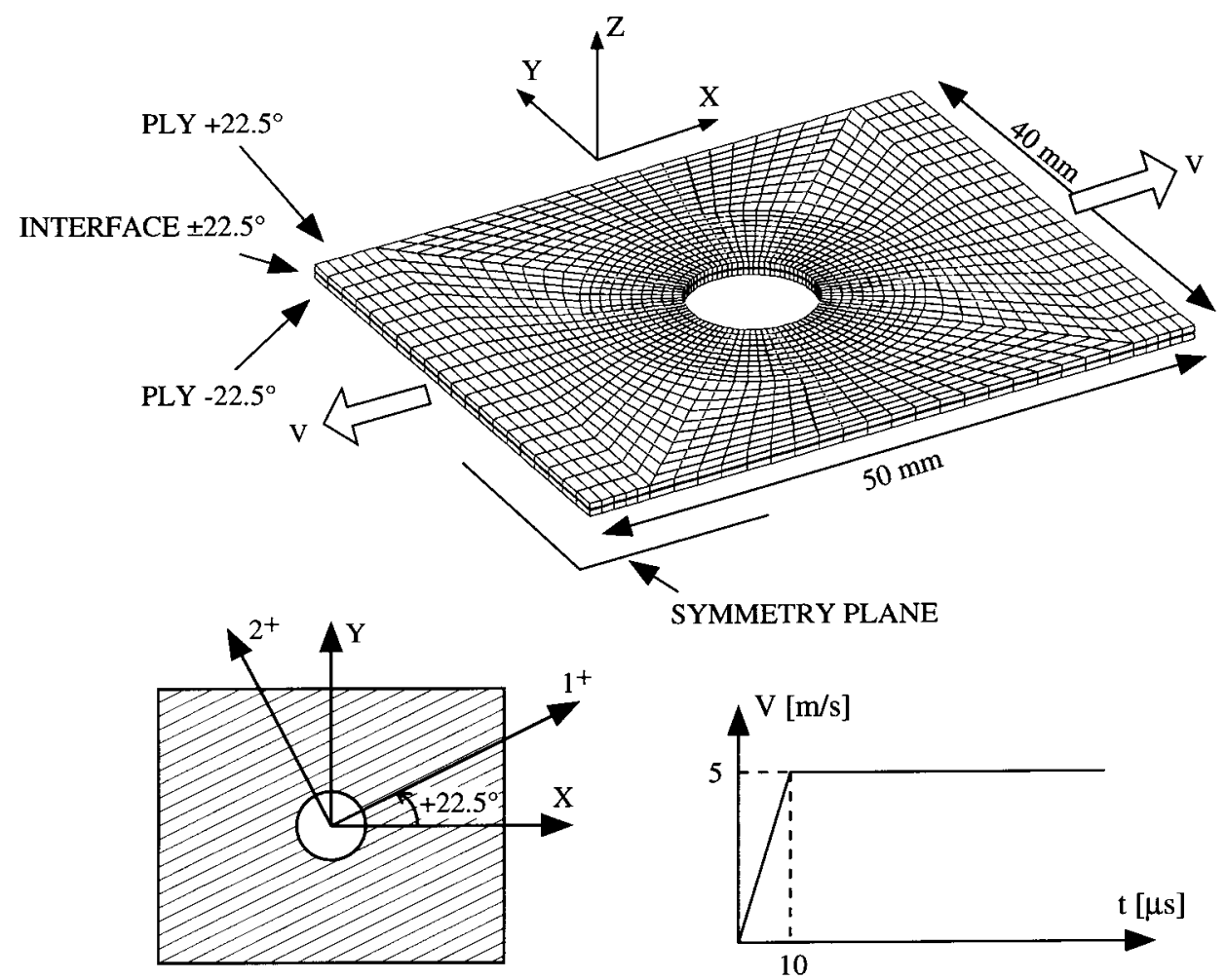

Fig. 16. Holed laminate submitted to dynamic tension loading.

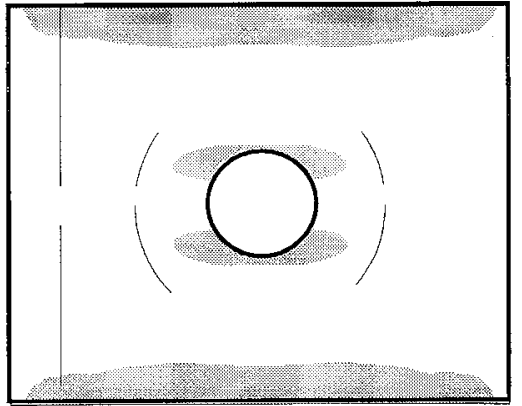

$\mathrm{t}=50 \mu \mathrm{s}$
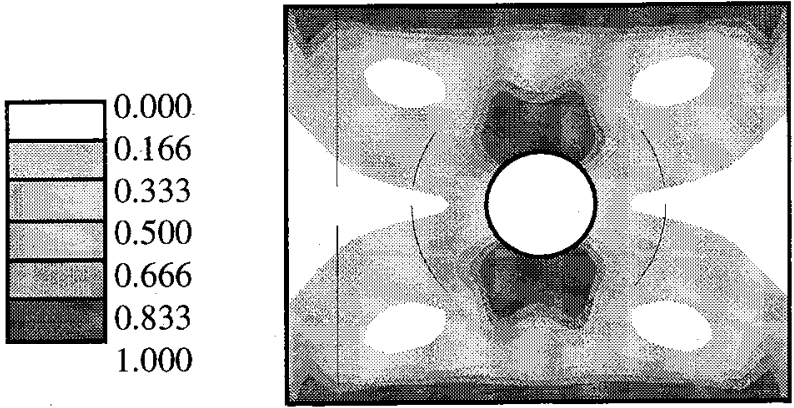

$\mathrm{t}=100 \mu \mathrm{s}$

Fig. 17. Interface damage map at several times.

\section{Delamination computation in dynamics}

An example of a 3D finite element computation is presented in order to demonstrate the ability of the damage mesomodel to predict the response of a composite structure in dynamics until its ultimate fracture. This response is computed using the explicit dynamic code LS-DYNA3D [46]. Fig. 16 defines the studied structure and its loading. It is a $\left[+22.5^{\circ}-22.5^{\circ}\right]_{\mathrm{s}}$ holed laminated plate; the material is a SiC/MAS-L composite with silicon carbide fibres and a glass matrix made by Aerospatiale. The fibre stiffness (200 GPa) is higher than the matrix stiffness $(75 \mathrm{GPa})$, and cracks first appear in the matrix [5]. Let us note that reasonable values have been chosen for the material constants of the interlaminar interface model. In particular, the values of the critical times $\tau_{\mathrm{c}}$ and $\tau_{\mathrm{c}}^{\prime}$ and the constants $a$ and $a^{\prime}$ are: 


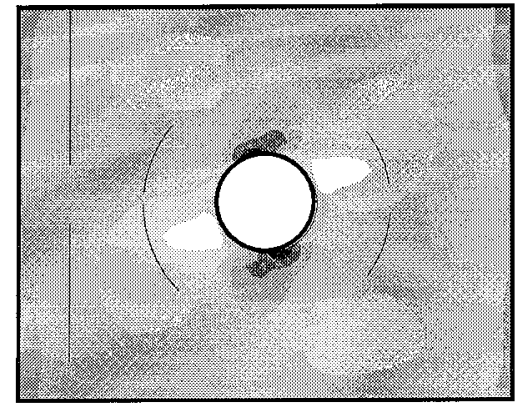

Ply $-22.5^{\circ}$

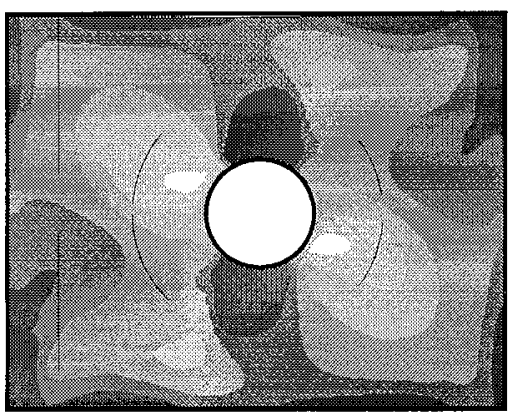

Ply $-22.5^{\circ}$

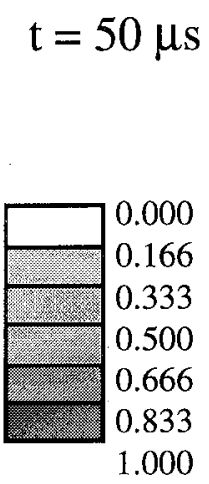

$$
\mathrm{t}=100 \mu \mathrm{s}
$$

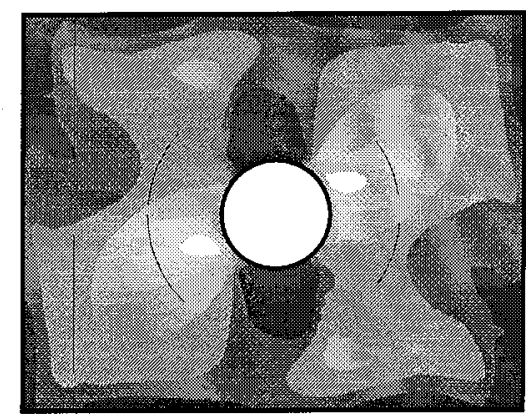

Ply $+22.5^{\circ}$

Fig. 18. Shear damage maps for the plies at several times.

$$
\begin{aligned}
& \tau_{\mathrm{c}}=\tau_{\mathrm{c}}^{\prime}=2 \mu \mathrm{s}, \\
& a=a^{\prime}=1 .
\end{aligned}
$$

Several computations have been performed especially for the stacking sequence $\left[n 0^{\circ}\right]_{s}$. These reasonable constant values correspond to a fracture zone size whose order of magnitude corresponds to the ply's thickness.

Fig. 17 reveals the degradation of the $\left[ \pm 22.5^{\circ}\right]$ interface; the dark area represents the completely destroyed zone and then the delamination crack.

Figs. 18 and 19 present the microcracking intensity maps and the fibre-direction damage maps at different times. It is clear that a transverse crack orthogonal to the fibres appears and then grows inside each ply. One can consider that the final fracture occurs around $t=100 \mu \mathrm{s}$; the size of the transverse cracks is about $2 \mathrm{~mm}$.

Last, the global load versus the prescribed displacement is plotted in Fig. 20. No particular numerical difficulty with respect to time discretisation and mesh sensitivity has appeared.

\section{Conclusion}

The laminate mesomodel proposed herein is able to compute the intensities of the damage mechanisms inside both the plies and the interfaces at any time, until final fracture; the main limitation for severe dynamic loadings is that the dynamic wavelength has to be larger than the thickness of the plies. Simulations have shown the macrocracks' initiation and propagation. Comparisons with experimental results have proved to be very satisfactory. 


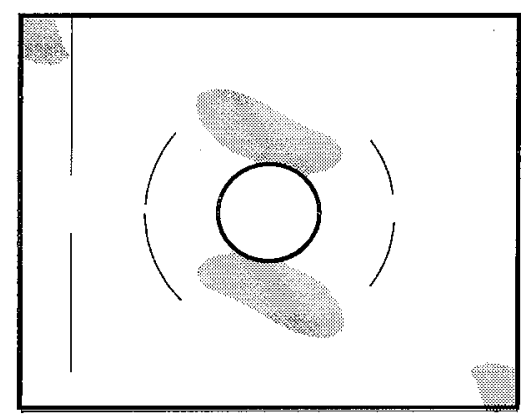

Ply $-22.5^{\circ}$

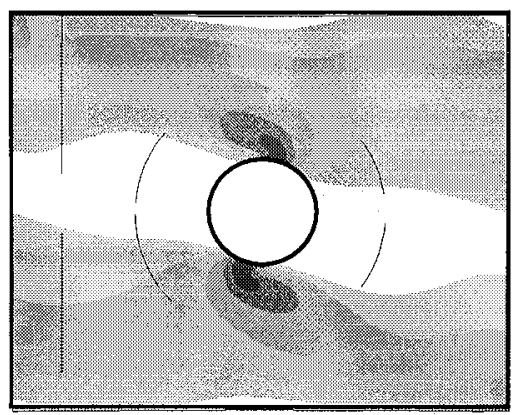

Ply $-22.5^{\circ}$ $\mathrm{t}=50 \mu \mathrm{s}$

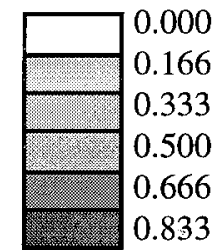

0.000

0.166

0.333

0.500

0.833

1.000

$\mathrm{t}=100 \mu \mathrm{s}$

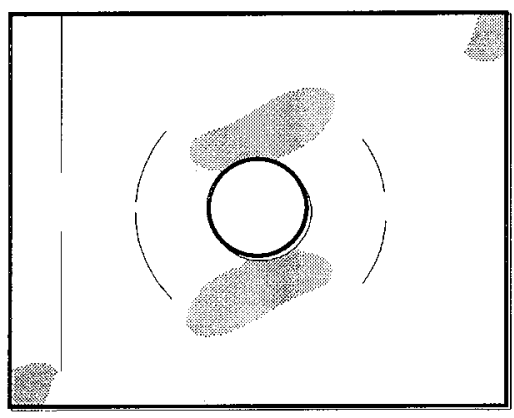

Ply $+22.5^{\circ}$

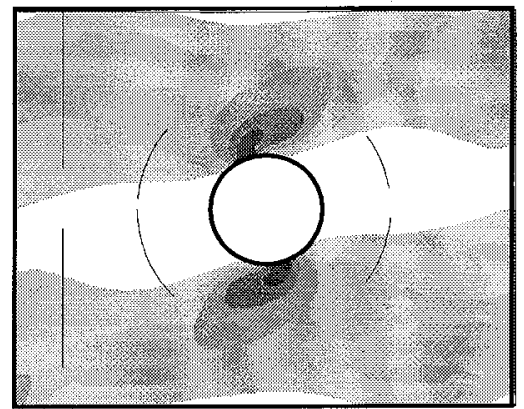

Ply $+22.5^{\circ}$

Fig. 19. Longitudinal damage maps for the plies at several times.

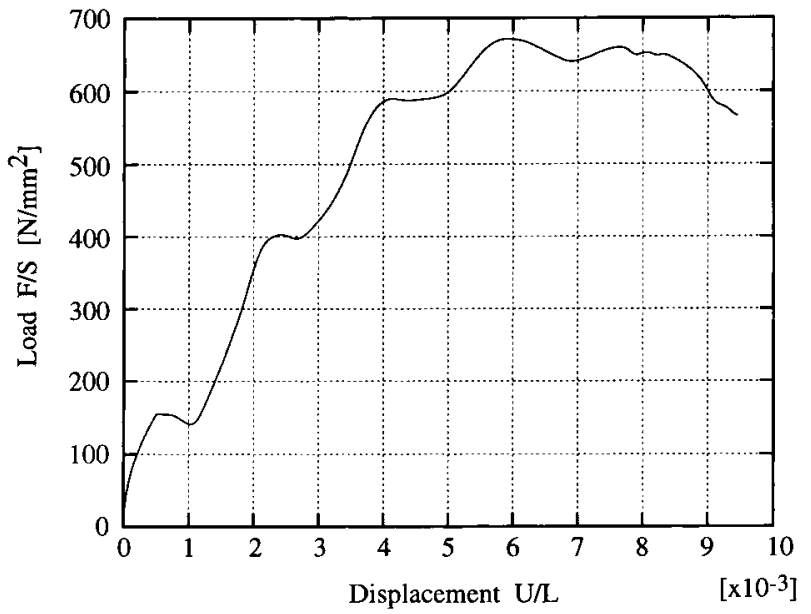

Fig. 20. Global load versus the prescribed displacement.

However, the computations performed with such a mesomodel do generate very large computational times. One present challenge is to develop a more effective computational strategy and, in particular, to use parallel computers. Another challenge is to extend what has been carried out for laminates to other composite structures for which damage models have already been derived ([26,47]). 


\section{References}

[1] P. Ladevèze, Sur la mécanique de l'endommagement des composites, in: C. Bathias, D. Menkès (Eds.), Comptes-Rendus des JNC5, Pluralis Publication, Paris, 1986, pp. 667-683.

[2] P. Ladevèze, E. Le Dantec, Damage modeling of the elementary ply for laminated composites, Composite Sci. Technol. 43 (3) (1992) 257-267.

[3] O. Allix, P. Ladevèze, E. Vitecoq, Modelling and identification of the mechanical behaviour of composite laminates in compression, Composite Sci. Technol. 51 (1994) 35-42.

[4] O. Allix, N. Bahlouli, C. Cluzel, L. Perret, Modelling and identification of temperature-dependent mechanical behaviour of the elementary ply in carbon/epoxy laminates, Composite Sci. Technol. 56 (1996) 883-888.

[5] A. Gasser, P. Ladevèze, P. Peres, Damage modelling for a laminated ceramic composite, Mater. Sci. Engrg., to appear 1998.

[6] C.T. Herakovich, Mechanics of Fibrous Composites, Wiley, New York, 1998.

[7] P. Ladevèze, About a damage mechanics approach, in: D. Baptiste (Ed.), Mechanics and Mechanisms of Damage in Composite and Multimaterials MEP, 1989, pp. 119-142.

[8] O. Allix, P. Ladevèze, Interlaminar interface modelling for the prediction of laminate delamination, Composite Structures 22 (1992) 235-242.

[9] O. Allix, P. Ladevèze, D. Lévêque, L. Perret, Identification and validation of an interface damage model for delamination prediction, in: D.R.J. Owen, E. Onate, E. Hinton (Eds.), Computational Plasticity, Spain, Barcelona, 1997, pp. 1139-1147.

[10] O. Allix, J.F. Deü, Delay-damage modeling for fracture prediction of laminated composites under dynamic loading, Engrg. Trans. 45 (1997) 29-46.

[11] A. Highsmith, K.L. Reifsnider, Stiffness reduction mechanism in composite material, in: ASTM-STP 775, Damage in Composite Materials, 1982, pp. 103-107.

[12] R. Talreja, Transverse cracking and stiffness reduction in composite laminates, J. Composite Mater. 19 (1985) $355-375$.

[13] D.H. Allen, Damage evolution in laminates, in: R. Talreja (Ed.), Damage Mechanics of Composites Materials, Elsevier, Amsterdam, 1994, pp. 79-114.

[14] J.L. Chaboche, O. Lesné, T. Pottier, Continuum damage mechanics of composites: Towards a unified approach, in: G.Z. Voyiadjis, J.W. Wu, J.L. Chaboche (Eds.), Damage Mechanics in Engineering Materials, Elsevier, Amsterdam, 1998 , pp. 3-26.

[15] G.Z. Voyiadjis, J.W. Wu, J.L. Chaboche, Damage Mechanics in Engineering Materials, Elsevier, Amsterdam, 1998.

[16] Z.P. Bazant, G. Pijaudier-Cabot, Non local damage: Continuum model and localisation instability, J. Appl. Mech. ASME 55 (1988) 287-294.

[17] T. Belytschko, D. Lasry, Localisation limiters and numerical strategies softening materials, in: J. Mazars, Z.P. Bazant (Eds.), Elsevier, Amsterdam, 1988, pp. 349-362.

[18] Z.P. Bazant, Z. Bittnar, M. Jirasek (Eds.), Fracture and Damage in Quasibrittle Structures, Elsevier, Amsterdam, 1994.

[19] P. Perzyna, Dynamic localized fracture in inelastic solids, in: G.Z. Voyiadjis, J.W. Wu, J.L. Chaboche (Eds.), Damage Mechanics in Engineering Materials, Elsevier, Amsterdam, 1998, pp. 183-202.

[20] L.J. Slyuis, R. de Borst, Wave propagation and localisation in a rate-dependent cracked medium: Model formulation and one dimensional examples, Int. J. Solids and Structures 29 (1992) 2945-2958.

[21] J.F. Dubé, G. Pijaudier-Cabot, C. La Borderie, Rate dependent damage model for concrete in dynamics, J. Engrg. Mech. 122 (1996) 939-947.

[22] B. Loret, J.H. Prevost, Dynamic strain localization in elasto- (visco-)plastic solids, Part 1. General formulation and onedimensional examples, Comput. Meth. Appl. Mech. Engrg. 83 (1990) 247-273.

[23] A. Needleman, Material rate dependence and mesh sensitivity in localization problems, Comput. Meth. Appl. Mech. Engrg. 67 (1988) 69-85.

[24] P. Ladevèze, Towards a fracture theory, in: D.R.J. Owen, E. Onate, E. Hinton (Eds.), Proceedings of the Third International Conference on Computational Plasticity, Part II, Pineridge Press, Cambridge, 1992, pp. 1369-1400.

[25] P. Ladevèze, A damage computational method for composite structures, J. Computer and Structure 44 (1/2) (1992) $79-87$.

[26] P. Ladevèze, A damage computational approach for composites: Basic aspects and micromechanical relations, Comput. Mech. 17 (1995) 142-150.

[27] P. Ladevèze, O. Allix, L. Gornet, D. Lévêque, L. Perret, A computational damage mechanics approach for laminates: Identification and comparison with experimental results, in: G.Z. Voyiadjis, J.W. Wu, J.L. Chaboche (Eds.), Damage Mechanics in Engineering Materials, Elsevier, Amsterdam, 1998, pp. 481-500.

[28] L. Daudeville, P. Ladevèze, A damage mechanics tool for laminate delamination, J. Composite Structures 25 (1993) $547-555$.

[29] D. Lévêque, Analysis of laminate delamination strength: Interlaminar interface model identification, Doctor Thesis, ENS Cachan, 1998.

[30] O. Allix, D. Lévêque, L. Perret, Interlaminar interface model identification and forecast of delamination in composite laminates, Composite Sci. Technol. 56 (1998) 671-678.

[31] Z.P. Bazant, T.B. Belytschko, Wave propagation in a strain softening bar: Exact solution, J. Engrg. Mech. 111 (1985) $381-389$.

[32] C. Hoff, T.J.R. Hugues, G. Hulbert, P.J. Pahl, Extended comparison of Hilbert-Hugues-Taylor $\alpha 1-\mathrm{method}$ and the $\theta 1-\mathrm{method}$, Comput. Meth. Appl. Mech. Engrg. 76 (1989) 87-93.

[33] J.C. Schellekens, R. De Borst, A non-linear finite element approach for the analysis of mode I-free edge delamination in composites, Int. Journal Solids Structures 30 (9) (1993) 1239-1253.

[34] O. Allix, A. Corigliano, P. Ladevèze, Damage analysis of interlaminar fracture specimens, Composite Structures 31 (1995) 61-74.

[35] G. Beer, An isoparametric joint/interface element for finite element analysis, Int. J. Numer. Meth. Engrg. 21 (1985) 585-600. 
[36] J.M. Whithney, Experimental characterization of delamination fracture, in: N.J. Pagano (Ed.), Interlaminar Response of Composite Materials, Comp. Mat. Series 5 (1989) 111-239.

[37] H.J. Albertsen, J. Ivens, P. Peters, M. Wevers, I. Verpoest, Interlaminar fracture toughness of CFRP influenced by fibre surface treatment: Part 1: Experimental results, Composite Sci. Technol. 54 (1995) 133-145.

[38] R.Y. Kim, Experimental observations of free-edge delamination, in: N.J. Pagano (Ed.), Interlaminar Response of Composite Materials, pp. 111-160.

[39] P. Davis, Measurement of GIc and GIIc in CarbonlEpoxy composites, Composite Sci. Technol. 39 (1990) $193-205$.

[40] A.J. Russell, K.N. Street, Moisture and temperature effects on the mixed-mode delamination fracture of unidirectional graphite/ epoxy, in: W.S. Johnson (Ed.), Delamination and Debonding of Materials, ASTM STP 876, Philadelphia, 1985, pp. 349-370.

[41] T.K. O'Brien, Characterisation of delamination onset and growth in a composite laminate, in: K.L. Reifsnider (Eds.), Damage in Composite Materials, ASTM-STP 775, 1982, pp. 140-167.

[42] F.W. Crossman, A.S.D. Wang, The dependence of transverse cracking and delamination on ply thickness in graphite/epoxy laminates, in: K.L. Reifsnider (Ed.), Damage in Composite Materials, ASTM-STP 775, 1982, pp. 118-139.

[43] P. Robinson, D.Q. Song, A modified DCB specimen for mode I testing of multidirectional laminates, Composite Sci. Technol. 26 (1992) 1554-1577.

[44] C. Bathias, Une revue des méthodes de caractérisation du délaminage des matériaux composites, in: O. Allix, M.L. Benzeggagh (Eds.), Délaminage: Bilan et perspectives, Journée AMAC/CSMA, Cachan, 1995.

[45] O. Allix, Damage analysis of delamination around a hole, in: P. Ladevèze, O.C. Zienkiewicz (Eds.), New advances in Computational Structural Mechanics, Elsevier, Amsterdam, 1992, pp. 411-421.

[46] J.O. Hallquist, LS-DYNA3D Theoretical Manual, Livermore Software Technology Corporation, Livermore, USA, 1991.

[47] P. Ladevèze, Modeling and simulation of the mechanical behavior of CMCs, in: A.G. Evans, R. Naslain (Eds.), High-temperature Ceramic-Matrix Composites, Ceramic Transaction, 1995, pp. 53-63.

[48] H.D. Espinoza, On the dynamic shear resistance of ceramic composites and its dependence on applied multiaxial deformation, Int. J. Solids and Structures (1995) 3105-3128. 